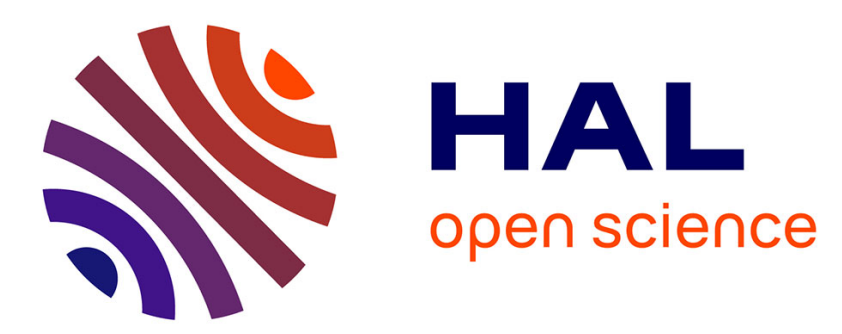

\title{
Relationships between human activity and biodiversity in Europe at the national scale: spatial density of human activity as a core driver of biodversity erosion
}

Frédéric Gosselin, J.M. Callois

\section{- To cite this version:}

Frédéric Gosselin, J.M. Callois. Relationships between human activity and biodiversity in Europe at the national scale: spatial density of human activity as a core driver of biodversity erosion. Ecological Indicators, 2018, 90, pp.356-365. 10.1016/j.ecolind.2018.03.010 . hal-02499878

\section{HAL Id: hal-02499878 \\ https://hal.science/hal-02499878}

Submitted on 5 Mar 2020

HAL is a multi-disciplinary open access archive for the deposit and dissemination of scientific research documents, whether they are published or not. The documents may come from teaching and research institutions in France or abroad, or from public or private research centers.
L'archive ouverte pluridisciplinaire HAL, est destinée au dépôt et à la diffusion de documents scientifiques de niveau recherche, publiés ou non, émanant des établissements d'enseignement et de recherche français ou étrangers, des laboratoires publics ou privés. 


\title{
Relationships between human activity and biodiversity in Europe at the national scale: spatial density of human activity as a core driver of biodversity erosion
}

\author{
Frédéric Gosselin ${ }^{1}$ and Jean-Marc Callois ${ }^{2}$ \\ ${ }^{1}$ Irstea, UR EFNO, Domaine des Barres, F-45290 Nogent-Sur-Vernisson, France. Mail : \\ frederic.gosselin@irstea.fr \\ ${ }^{2}$ Irstea, Département Territoires, 1 rue Pierre-Gilles de Gennes, F-92761 Antony Cedex, \\ France. Mail : jean-marc.callois@irstea.fr
}

\section{Abstract}

Many empirical studies have analyzed the relationship between human activity and the environment.

Some of these have focused on the potentially negative impacts of human activity on the environment.

Some others have tried to identify socio-political variables that could be at play in this relationship.

Herein, we used well-adapted statistical methods to study the relationship between human activity and biodiversity in Europe at the country level; we worked with classical biodiversity indicators (two state indicators, two pressure indicators and one response indicator) on the one hand, and socio-economic variables on the other hand. We found strong relationships between economic variables and pressure indicators (related to soil sealing) as well as state indicators (related to the proportion of extinct and threatened species). However, there was no relationship between economic variables and the response indicator (related to the proportion of protected area). Though we did find significant relationships between some sociological variables and biodiversity indicators, the best models all included economic variables. These results cast a new light on an old issue: first, they reveal the pertinence of a set of variables related to the spatial density of human activity - either through economic growth or population levels; they also show that the impact of the spatial density of human activity on 
biodiversity indicators tends to decelerate - but not to decrease - as the spatial density of human activity increases. These results reveal the need for further studies involving these metrics.

Keywords: species imperilment; land sealing; protected areas; endangered species; economic growth; human population; social trust; indicators

\section{Introduction}

Ecological science has long included analyzes at the macro scale (see Arrhenius, 1921; Willis, 1922; and references in Brown, 1999; Gaston and Blackburn, 1999). Yet, this practice has only recently been formalized into a research program - called macroecology - with a strong emphasis on an empirical statistical approach to global patterns (Brown, 1999). This research program was inspired by (i) the recognition of human pressures at a scale so large they cannot simply be analyzed from smaller scale approaches (Brown, 1999; Gaston and Blackburn, 1999); (ii) the realization that empirical approaches to identifying patterns are as crucial in ecology as in other scientific disciplines (Peters, 1991; Brown, 1999; Gaston and Blackburn, 1999); and (iii) the increasing availability of databases at this macro scale (Brown, 1999). Quite surprisingly, although macroecology has extended its scope in terms of databases and scales, and has recognized the interest of the empirical approach, it remains centered on ecological objects (including geographical objects such as latitudinal gradients and topography). Indeed, neither of the two syntheses by Brown (1999) and Gaston and Blackburn (1999) include any reference to economic or demographic indicators as explanatory variables - other than their role in motivating the emergence of macroecology. Extending macroecology to socio-economic drivers and variables is all the more welcome since this could provide thought-provoking links to the social sciences. Indeed, the interplay between human pressures and ecological objects is under active investigation in the field of economics. Concern about the impact of economic activity on the environment began to rise in the 1950s, with the foundation of 
environmental economics as an independent field of economics; this movement accelerated in the late 1960s, after Garrett Hardin formalized the notion of the "tragedy of the commons". Early empirical studies mostly focused on environmental objects which were physical parameters $(\mathrm{CO} 2, \mathrm{NOx}$, $\mathrm{SO} 2 \ldots)$ rather than ecological phenomena. In an attempt to test the relationships between economic development and a wide array of environmental variables, Shafik (1994) pointed out that relationships can be very different according to the variables under study, and that no obvious pattern exists. Some of his results gave credit to the idea of a bell-shaped curve relating economic development and pollution, known as the Environmental Kuznets Curve, which was first introduced by Selden and Song (1994) and has since given rise to numerous attempts to identify macro-relations between environmental quality and aggregate economic parameters. Since the 1990s, the issue of the impact of economic activity on biodiversity has been growing, in both ecology (Wright, 1990) and economics (Krautkraemer, 1995). In one of the earliest crossnational studies focusing on biodiversity, Asafu-Adjaye (2003) tested the impact of variables related to human activity on several biodiversity variables (essentially the number of mammals, birds and vascular plants). As in other studies, he found different responses depending on the biodiversity metrics used. For example, there were significant impacts of human population density (HPD) and of ratio of protected area on species richness metrics (respectively negative and positive impacts). Per capita gross domestic product (GDPc) and ratio of artificialized or agricultural land had significant negative impacts on the average annual percentage change in the number of known mammal species. He also introduced institutional factors (economic freedom, black markets), but these variables had a strongly significant relationship only for the species richness of vascular plants. As in many other studies, the impacts tended to be higher for low-income countries, although the estimators were very noisy.

74 Focusing on the link between HPD and biodiversity, Luck (2007) reviewed the published empirical literature through a meta-analysis. Although the published literature was skewed geographically and taxonomically, he found positive correlations between HPD and various biodiversity metrics - mainly related to species richness: the level of biodiversity was greater in densely populated zones, which was possibly due to correlations between the two metrics and other parameters such as ecosystem 
productivity or solar energy availability. In contrast, there were some indications of more negative relationships between HPD and species extinction, but the evidence was judged weak (Luck 2007). Another series of results (Mikkelson et al., 2007; Holland et al., 2009) indicated that income inequality was a significant positive indicator of the proportion of globally threatened species, though only Holland et al. (2009) found that the logarithm of GDPc was a significantly negative indicator, with HPD having no significant relationship. On the whole, these results partly suggest that human activity per se might not be the most fundamental driver of biodiversity erosion.

The way human activity influences biodiversity might depend on much more than the level of economic activity or population size. Sociological and cultural factors may well be at play. First, national or regional cultures may be characterized by social values that are more or less favorable to the protection of biodiversity. Casual observation suggests that for a given level of human presence, there are very different attitudes across countries towards the quality of the environment. These differences in attitudes could significantly influence the quality of ecosystems at a macro level. Many studies can be found in the Convention for Biological Diversity (https://www.cbd.int/) that highlight the role of social values. Secondly, biodiversity protection may also be influenced by the general functioning of society. This is the object of the so-called "social capital" research program (Coleman, 1988; Dasgupta, 2000). In the same way the supra-national studies quoted above have tried to relate economic and environmental variables, social scientists have tried to prove that sociological indicators - in particular indicators of social values - influence economic development (Zak and Knack, 2001; Bjørnskov, 2006). The main indicators used in such studies are proxies for trust and participation in associations (see Callois and Schmitt, 2009, for a review of available indicators). Thirdly, one may wonder if there are not even more fundamental drivers of sociological characteristics. Hofstede (1980) built a 4-dimensional framework (later enlarged to six dimensions) to characterize national cultures. He claimed that these dimensions capture the anthropological features driving values and attitudes in society. The six dimensions are: power distance (i.e. acceptance of hierarchical power), individualism, uncertainty avoidance, masculinity, long-term orientation and hedonism. Using Hofstede's framework, Chambers and Hamer (2012) found that individuality and uncertainty avoidance are the 
main dimensions promoting economic growth. To our knowledge, few cross-country studies take into account such sociological or anthropological factors when explaining biodiversity (Asafu-Ajaye, 2003; Holland et al., 2009).

The aim of this paper is to deepen the understanding of the relationships between human activities and biodiversity variables by developing and comparing statistical models that link socio-economic indicators with biodiversity indicators at a national scale. We include not only classically targeted socio-economic variables but also more sociologically or anthropologically oriented variables. By comparing different types of socio-economic variables, we hope to identify the most relevant drivers of the human impacts on biodiversity and improve our understanding of their underlying mechanisms. With this general goal in mind, our main hypotheses were as follows:

i. Regarding response variables, a better understanding of biodiversity indicator responses to socio-economic variables can be achieved by using not only indicators of the state of biodiversity but also metrics that might be the more proximal causes of these variations or metrics that might be explained by the state of biodiversity (as e.g. in Luck, 2007; Butchart et al., 2010). Our general hypothesis is that human activity does indeed have some impact on these different variables related to biodiversity. Our approach can therefore be interpreted within the Drivers-Pressures-State-ImpactResponse (DPSIR) framework developed by the European Environmental Agency (see for instance Gari et al., 2015; Dietz 2017 for a discussion of the origin and evolution of the DPSIR framework and its applications). We are not only studying the relationships between Drivers of change (here, socio-economic variables) and the State of biodiversity, but also between these Drivers and potentially more proximal causes of change than the Drivers - coined Pressures - or responses to Pressures and/or States of biodiversity, here associated with the notion of Response indicator. We selected the proportion of extinct species and the proportion of threatened species as State indicators, the proportion of protected area as the Response indicator and the proportion of sealed land and its increase as Pressure indicators. 
ii. Concerning explanatory variables, we considered both economic indicators of human activity and sociological and anthropological variables. Regarding the latter, we hypothesized that sociological and anthropological variables could act as primary drivers and thus would partly explain variations in biodiversity. As for the economic indicators of human activity, we used classical metrics related to economic growth and human population but we also hypothesized that Gross Domestic Product (GDP) should be scaled not per inhabitant but per area (square kilometer) to better reveal its relationship with biodiversity indicators. Indeed, past analyses - including those related to the Kuznets curve - have almost exclusively used the classical indicator, GDP per capita (GDPc) (three exceptions are Panayotou, 1997; Kaufmann et al., 1998; Liu et al. 2005). We suggest that GDP per area is a more logical indicator. Indeed, the level of pressure on biodiversity should first appear in relation to an area, rather than in relation to an inhabitant. For example, the level of wealth produced per inhabitant, whether high or low, may be irrelevant for biodiversity, provided human population density (HPD) is low. In contrast, pressures such as the level of resource extraction per unit area, waste generation per unit area or proportion of sealed area are directly linked with GDP per area (Panayotou, 1997).

\section{Material and methods}

\section{Biodiversity indicators}

The aim of our work was to relate relevant biodiversity indicators to socio-economic variables throughout Europe. We chose five indicators that are readily available at national level, as follows:

i. Two Pressure indicators related to soil sealing (or imperviousness): the percentage of surface area in the country sealed in 2009 (denoted as SEAL), and the annual increase in sealing between 2006 and 2009 expressed as a percentage (denoted as iSEAL); 
ii. Two indicators of the State of biodiversity: the proportion of extinct and threatened species (denoted as Extinct and Threatened respectively) in each country for ten different taxonomic groups (vascular plants, bryophytes, mammals, birds, freshwater fishes, reptiles, amphibians, dragonflies, grasshoppers and trees); (combining the four different International Union for Conservation of Nature (IUCN) types of protected areas). or imperviousness is a classical land use indicator. It can proxy the degree of land-cover change due to urban or industrial development and related increases in transport infrastructure. Since habitat loss is an undisputed cause of biodiversity erosion (Fahrig, 2003), sealing is often used as a Pressure 173 indicator for biodiversity.

174 Concerning State of biodiversity indicators, we chose (i) the proportion of extinct species (corresponding to the IUCN Categories or Extinct in the Wild) in each country and for different taxonomic groups to indicate a past "state" of biodiversity; and (ii) the proportion of threatened species in each country and for different taxonomic groups to indicate the current state of biodiversity. These proportions indicate the part of biodiversity that has eroded (for extinct species) or that is still eroding (for threatened species) over time. They are therefore classically used at the territory level as indicators of biodiversity State. We did not select species richness or the total number of extinct or threatened species, because the two variables are very likely to share dependency on territory area and other environmental variables with socio-economic variables, thus obscuring any relationship they might have with those socio-economic variables (cf. Luck, 2007 in the case of HPD, and Dullinger et al., 2013). We used data from Essl et al. (2013) for both threatened and extinct species as well as the total number of species for different taxonomic and ecological groups to calculate the proportions of extinct and threatened species in each country. The lists for extinct and threatened species correspond to national Red Lists (see SM for additional comments). Essel et. al.'s 
data set incorporates ten ecological or taxonomic groups: vascular plants, bryophytes, mammals,

189 birds, freshwater fishes, reptiles, amphibians, dragonflies and grasshoppers. We added similar data for 190 trees from Forest Europe et al. (2011, Table A4.9).

191 Finally, as the Response variable, we considered the proportion of protected area. Indeed, creating protected areas is a classical component of the public policies designed to improve the state of biodiversity and reduce some of the pressures on it (e.g. intensification of resource management or land sealing). As an example, CBD Aichi target 11 aims to protect at least 17\% of the terrestrial area. We used the IUCN data on protected areas for terrestrial ecosystems by EuroStat in 2013. The four IUCN categories of protected areas that we analyzed were: categories Ia and Ib(Strict Nature Reserves and Wilderness Areas respectively), which we combined in Category I; Category II, corresponding to National Parks; Category III, for reserves around Natural Monuments or Features; and Category IV, for Habitat or Species Management Areas.

The five different indicators defined above are classically used in territorial reporting. They have, for example, been proposed as general indicators of biodiversity in France (http://indicateursbiodiversite.naturefrance.fr).

\section{Explanatory variables}

204 We chose our explanatory variables among socio-economic variables, that were potential Drivers in a 205 DPSIR framework. We first tested two classical indicators of human activity: gross domestic product 206 (GDP) and human population density (HPD). As explained in the introduction, we not only tested 207 GDP per captia but GDP per area as well because we conjectured that the spatial density of economic activity would have a greater significance than simple per capita economic development. GDP per area is a simple way to calculate an ecological footprint, as defined in the seminal work of Ehrlich and

210 Holdren (1971). We tested the role of HPD by combining it with GDP per capita (as in Holland et al., 2112009 and Dullinger et al., 2013). In addition, we examined rural and urban population density 212 separately; this distinction allowed us to investigate the possible role of heterogeneity in human 213 pressure, which has seldom been done for biodiversity. We supposed that the pressure human 214 population exerts on biodiversity indicators should be scaled by area to facilitate a comparison among 
215 territories; therefore, although some authors retained total population size (Brown and Laband, 2006;

216 McKinney, 2002a - but see: McKinney, 2002b), we focused on HPD, as many previous studies have 217 done (cf. synthesis in Luck, 2007; Holland et al., 2009).

218 We also included sociological factors, which, to our knowledge, had never before been taken

219 into account. We tested a structured array of variables, belonging to three main categories as

220

221

222

223

224

225

226

227

228

229

230

231

232

233

234

235 explained in the Introduction:

- Fundamental Cultural attributes (hereafter FC), which include six variables taken from Hofstede (1980), related to power distance, individualism, uncertainty avoidance, masculinity, long-term orientation and hedonism.

- Social Capital indicators (SC), from the UNDP database, which include general social trust, community functioning, and trust in the national government (http://hdr.undp.org/fr/data).

- Indicators of concern for the environment (EC), including the proportion of the population declaring voluntary work in environmental associations, the proportion of the population claiming they trust these associations, the proportion of the population claiming that "man should reign over nature", and the proportion of the population claiming that "interference with nature is often disastrous". For these variables, we used 2008 European Values Study data (http://www.europeanvaluesstudy.eu/).

The three categories (FC, SC and EC) occur along a gradient, ranging from fundamental attributes driving human behavior to specific measurements of environmental concern. We used the three categories to try to identify the most fundamental drivers of human activity's impact on biodiversity. We hypothesized that, if the Hofstede variables (FC) were the most relevant explanatory variables, this would imply that human impact on nature is deeply rooted in national cultures. If environmental concern (EC) proxies were the most relevant, a policy promoting environmental awareness might be able to quickly improve biodiversity. If the intermediate category of social capital (SC) turned out to be the most relevant, policies promoting sociability and good institutions would seem to be the most appropriate for improving biodiversity. 
243 The list of socio-economic variables together with their sources and a summary of their values are

244 provided in Tables 1 and SM1. Correlations between explanatory variables are displayed in Figure

245 SM1 in the Supplementary Materials section. Some patterns emerge from these figures that helped us

246 shape the statistical models we tested. In particular, we initially intended to fit a model including GDP

247 per unit area and (total or urban) HPD. Yet the correlation between these variables was so high that

248 we did not use them together within the same model. Two other clearly noticeable associations

249 occurred: there were a strong positive correlation (i) between Environmental Association membership

250 (MEMB.2008) and the two above-mentioned metrics (GDPa, HPD or HPDu); and (ii) between GDP

251 per capita and social capital variables (TRUTSP \& COMMUN), which was expected.

252 The overall list of countries we considered was the same as the one in Essl et al. (2013), and included

25338 European countries plus Israel. However, the actual countries included in the tests depended on the

254 availability of the socio-economic data (cf. infra). Moreover, to avoid the peculiarities of very small areas, we did not take very small countries (Cyprus, Malta and Luxembourg) into account, as e.g.

256 Dullinger et al. (2013) did.

\section{Statistical models and hypotheses}

As in Brown and Laband (2006), our modeling strategy was based on the estimation and comparison of several simple statistical models. We did not combine different metrics into a single, global metric nor did we estimate a single statistical, multiple regression model that would have included all the variables; we thus avoided technical and interpretative problems related to correlations between variables. Instead, we estimated and compared the twelve main models described in Table 2. Except for the null model, each model incorporated two socio-economic variables related to a specific theme as explanatory variables. We chose to limit the number of variables in our models since we only had a limited number of countries in our data set ( 23 for Pressure indicators, 24 for species State indicators, 22 for Response indicators; cf. Harrell (2001)'s guidelines on the relationship between sample size and number of explanatory variables). 
the countries in our extended data set). We also included a Kuznets model based on the Kuznets curve

271 hypothesis which posits that the relationship between environmental State and GDP is quadratic. For

272 the Kuznets curve, we tested two forms: Kuznets, the classical one, involving GDP per capita (GDPc),

273 and a new form, Kuznetsa, involving GDP per area (GDPa). We then included a more precise HPD

274 model (demo) that separated urban HPD from rural HPD. Since some explanatory variables had no

275 clearly symmetrical distribution, we also fitted a version of these models with the logarithm of the

276 explanatory variables (leco, lKuznets, lKuznetsa and ldemo; see Table 2). These models of human

277 presence/activity were complemented by models based on sociological attributes. We included one

278 model based on Hostede's fundamental cultural attributes $(F C)$, one model for social capital

279 indicators $(S C)$ - Trust in other People and Trust in the Government; and two models related to

280 concern for the environment (EC), one based on participation and confidence in Environmental NGOs

$281(N G O)$ and one based on Environmental Related Values (ERV; cf. Tables 1 \& SM1). For the $F C$

282 variables, we selected two dimensions: "long-term orientation" and "hedonism". The first reflects a

283 preference for the present, which is a fundamental parameter in economic behavior while the second

284 concerns the focus given to material goods.

\begin{tabular}{|c|c|c|c|}
\hline Name of variable & $\begin{array}{l}\text { Explanation, unit and } \\
\text { source }\end{array}$ & $\begin{array}{l}\text { Main model including the } \\
\text { variable }\end{array}$ & $\begin{array}{l}\text { Summary of } \\
\text { variations of the } \\
\text { variable }\end{array}$ \\
\hline$\overline{G D P c}$ & $\begin{array}{l}\text { Gross Domestic Product } \\
\text { per inhabitant in } 2013 \\
\text { (unit: Euros PPS; } \\
\text { source: Forest Europe } \\
\text { 2015, Table 1, p.243) }\end{array}$ & Eco \& Kuznets & $\begin{array}{l}\text { Untransformed: } \\
23517( \pm 10423) \\
{[3500 ; 49600]} \\
\text { Log: } 9.95( \pm \\
0.54)[8.16 ; \\
10.81]\end{array}$ \\
\hline GDPa & $\begin{array}{l}\text { Gross Domestic Product } \\
\text { per } 10 \text { ha in } 2013 \text { (unit: }\end{array}$ & Kuznets & $\begin{array}{l}\text { Untransformed: } \\
32847( \pm 38647)\end{array}$ \\
\hline
\end{tabular}




\begin{tabular}{|c|c|c|c|}
\hline & $\begin{array}{l}\text { Euros PPS; source: } \\
\text { Forest Europe 2015, } \\
\text { Table 1, p.243) }\end{array}$ & & $\begin{array}{l}\text { [917; 173767] } \\
\text { Log: } 9.82( \pm \\
1.15)[6.82 ; \\
12.07]\end{array}$ \\
\hline $\mathrm{GDPc}^{\wedge} 2$ & $\begin{array}{l}\text { Gross Domestic Product } \\
\text { per inhabitant in } 2013 \\
\text { (unit: Euros PPS; } \\
\text { source: Forest Europe } \\
\text { 2015, Table 1, p.243) }\end{array}$ & Eco \& Kuznets & $\begin{array}{l}\text { Untransformed: } \\
658053667 \\
( \pm 551967811) \\
{[12250000 ;} \\
2460160000] \\
\log (\mathrm{GDPc})^{\wedge} 2: \\
99.24( \pm 10.45) \\
{[66.60 ; 116.89]}\end{array}$ \\
\hline $\mathrm{GDPa}^{\wedge} 2$ & $\begin{array}{l}\text { Gross Domestic Product } \\
\text { per } 10 \text { ha in } 2013 \text { (unit: } \\
\text { Euros PPS; source: } \\
\text { Forest Europe 2015, } \\
\text { Table 1, p.243) }\end{array}$ & Kuznets & $\begin{array}{l}\text { Untransformed: } \\
2.52 \mathrm{e}+09 \\
( \pm 6.02 \mathrm{e}+09) \\
{[8.41 \mathrm{e}+05 ;} \\
3.02 \mathrm{e}+10] \\
\log (\mathrm{GDPa})^{\wedge} 2: \\
97.80( \pm 22.29) \\
{[46.52 ; 145.58]}\end{array}$ \\
\hline HPD & Population density & Eco & $\begin{array}{l}\text { Untransformed: } \\
123( \pm 106)[9 ; \\
498] \\
\text { Log: } 4.48( \pm \\
\text { 0.89) }[2.20 ; 6.21]\end{array}$ \\
\hline HPDu & $\begin{array}{l}\text { Urban population } \\
\text { density }\end{array}$ & Demo & $\begin{array}{l}\text { Untransformed: } \\
93( \pm 99)[7 ; 445]\end{array}$ \\
\hline
\end{tabular}




\begin{tabular}{|c|c|c|c|}
\hline & & & $\begin{array}{l}\text { Log: } 4.12( \pm \\
0.93)[1.90 ; 6.10]\end{array}$ \\
\hline HPDr & Rural population density & Demo & $\begin{array}{l}\text { Untransformed: } \\
31( \pm 20)[1 ; 64] \\
\text { Log: } 3.07( \pm \\
1.10)[-0.22 ; 4.15]\end{array}$ \\
\hline H.LT & $\begin{array}{l}\text { Long-term orientation } \\
\text { (source: Hofstede 1980) }\end{array}$ & $\mathrm{FC}$ & $\begin{array}{l}59.7( \pm 17.6)[24 ; \\
83]\end{array}$ \\
\hline H.HED & $\begin{array}{l}\text { Hedonism (source: } \\
\text { Hofstede 1980) }\end{array}$ & $\mathrm{FC}$ & $\begin{array}{l}38.8( \pm 19.4)[13 ; \\
70]\end{array}$ \\
\hline TRUSTP & $\begin{array}{l}\text { Trust in other people } \\
\text { (\%) (source: UNDP } \\
2013 \text { ) }\end{array}$ & $\mathrm{SC}$ & $\begin{array}{l}27.4( \pm 15.8)[7 \\
74]\end{array}$ \\
\hline TRUSTG & $\begin{array}{l}\text { Trust in the national } \\
\text { government (\%) (source: } \\
\text { UNDP 2013) }\end{array}$ & $\mathrm{SC}$ & $\begin{array}{l}38.0( \pm 16.1)[13 ; \\
77]\end{array}$ \\
\hline MEMB.2008 & $\begin{array}{l}\text { Rate of membership in } \\
\text { environmental } \\
\text { associations (source: } \\
\text { European Values Study } \\
\text { 2008) }\end{array}$ & Environmental NGOs & $5.3( \pm 6.7)[1 ; 36]$ \\
\hline CONFAE.2008 & $\begin{array}{l}\text { Trust in environmental } \\
\text { associations (\%) } \\
\text { (source: European } \\
\text { Values Study 2008) }\end{array}$ & Environmental NGOs & $\begin{array}{l}56.3( \pm 12.7)[25 ; \\
76]\end{array}$ \\
\hline REIGN.2008 & $\begin{array}{l}\text { Opinion that "man } \\
\text { should reign over }\end{array}$ & $\begin{array}{l}\text { Environment Related } \\
\text { Values }\end{array}$ & $\begin{array}{l}33.4( \pm 12.1)[17 ; \\
60]\end{array}$ \\
\hline
\end{tabular}




\begin{tabular}{|l|l|l|l|}
\hline & $\begin{array}{l}\text { nature" (\%) (source: } \\
\text { European Values Study } \\
\text { 2008) }\end{array}$ & & \\
\hline INTERF.2008 & $\begin{array}{l}\text { Opinion that } \\
\text { "interference with nature } \\
\text { is often disastrous" (\%) } \\
\text { (source: European } \\
\text { Values Study 2008) }\end{array}$ & Values & 96] \\
\hline
\end{tabular}

Table 1. List of socio-economic variables included in the main statistical models (cf. Table 2). The

287 summary of the variations of the variables across countries includes the mean $( \pm$ the standard

288 deviation) and in square brackets the minimum and maximum. Variations come from the model for

extinct species (these summary statistics do not include the repetition of data when a single country is included repeatedly in the analysis).

\begin{tabular}{|l|l|l|}
\hline Model name & $1^{\text {st }}$ main explanatory variable & $2^{\text {nd }}$ main explanatory variable \\
\hline Null & - & \\
\hline Economic (eco) & GDPc & - \\
\hline Economic $-\log$ (leco) & $\log (\mathrm{GDPc})$ & $\mathrm{HPD}$ \\
\hline Kuznets (Kuznets) & GDPc & $\log (\mathrm{HPD})$ \\
\hline Kuznets - log (lKuznets) & $\log (\mathrm{GDPc})$ & $\mathrm{GDPc}{ }^{\wedge} 2$ \\
\hline Kuznets- area (Kuznetsa) & GDPa & $\log (\mathrm{GDPc})^{\wedge} 2$ \\
\hline
\end{tabular}




\begin{tabular}{|l|l|l|} 
Kuznets $-\log$ area & $\log (\mathrm{GDPa})$ & $\log (\mathrm{GDPa})^{\wedge} 2$ \\
\hline "Demography" (demo) & HPDu & HPDr \\
\hline "Demography" - log (ldemo) & $\log (\mathrm{HPDu})$ & $\log (\mathrm{RPOd})$ \\
\hline Fundamental Culture (FC) & H.LT & \\
\hline Social Capital (SC) & TRUSTP & H.HED \\
\hline Environmental NGOs (NGOs) & in NGOsMEMB.2008 & CONFAE.2008in NGOs \\
\hline Environment Related Values & REIGN.2008 & TRUSTG \\
\hline
\end{tabular}

Table 2. The twelve main statistical models estimated with their names and the main explanatory variables they contain. The meaning of the variables as well as information on their values can be found in Table 1.

\section{Statistical methods}

297 We used statistical methods with a priori relevant probabilistic properties relative to our data. Based on the lessons learned on partly similar data from Gosselin (2015), we paid careful attention to the potential over-dispersion of data as well as to the inclusion of random country effects. Indeed, in all

300 our statistical models for State and Response indicators, we simultaneously analyzed different

301 categories (i.e. either taxonomic groups or types of protected areas). This means that the same countries can correspond to several different values of the response variable; if this is not taken into 
account, it can potentially violate the independence hypothesis of the statistical models (Gosselin,

304 2015). A random country effect, which was assumed to follow a Gaussian distribution with a zero mean and an estimated standard deviation, was therefore introduced for State and Response indicators.

307 For the proportion of extinct or threatened species, we used a beta-binomial distribution to model the number of extinct or threatened species. In this model, the logit of the proportion of threatened or extinct species was equal to the linear combination incorporating the country random effect, the taxonomic group fixed effect and the effect of other socio-economic variables (cf. infra). We also modelled a dispersion parameter for the beta-binomial distribution - one different level of dispersion

312 per taxonomic group.

313 For the proportion of protected area and the percentage of sealed soil area (SEAL) and its increment (iSEAL), we used a zero-inflated beta distribution, which is a direct sub-product of the zero-inflated cumulative beta distribution that Herpigny and Gosselin (2015; MTUnlimited2 version) proposed to analyze plant cover class data. Here too, the logit of the mean proportion of protected areas or sealed area was equal to the same linear combinations as above. For the proportion of protected area, the type of protected area (among the four IUCN categories mentioned above) replaced the taxonomic group. For sealed area, we fitted a separate model for the two indicators (SEAL and iSEAL) and therefore did not include a random country effect in the corresponding models. Also, a dispersion parameter was estimated for each type of protected area (and globally for SEAL and iSEAL). Finally, a single extra parameter was estimated to model the probability of zeros, as proposed in Herpigny and

\section{Gosselin (2015; parameter d).}

324 We processed all the analyses with R software v. 3.3.2 (R Core Team, 2016). We used the Stan program embedded in R through the rstan library (Stan Development Team 2015) to estimate the above models. The priors of the hyper-parameters were mostly non-informative, except for the proportion of extinct species for which we had to introduce an upper bound at $\exp (10)$ for dispersion levels in order to obtain converging results. All the explanatory variables were centered and manually scaled to ensure a residual standard deviation of the variable of around 1 while keeping a clear control on the level of scaling for magnitude analyses. We ran between 200,000 and 350,000 iterations of 
three Markov chain trajectories. The warm-up period was 20,000. The thinning parameter was either

33210 or 30 (for Extinct). This ensured us a minimum of 10,000 (for Protected Area models) and around 33325,000 (for Extinct, Threatened, SEAL and iSEAL) independent values of the parameters. With this 334 setting, the models converged very well for the proportion of species, SEAL, iSEAL and well for the proportion of protected areas (Gelamn-Rubin Rhat statistic below 1.01 and 1.03 respectively; Gelman et al., 2004). et al. (2016). For State and Response indicators, we used the marginal version of the LOOIC for reasons discussed by Millar $(2009,2017)$ and because the country random effect introduced a number of parameters that was of the same order of magnitude as the number of observations. statistical significance and the magnitude of the relationships. For statistical significance, we used Bayesian quantiles based on beta random draws as in Gosselin (2011); we comment only those cases

344 with a p-value below 5\%. To judge the magnitude of Odds-ratios adapted to the magnitude analysis

345 framework proposed in ecology by e.g. Camp et al. (2008) and Barbier et al. (2009), we analyzed the 346 effect of an increase of one standard deviation at the linear combination level (on the log of odds 347 ratios) for each socio-economic variable according to guidelines adapted from Daniels et al. (1983) 348 (see Table 4 legend for more details). In a more explorative phase, for the socio-economic variables that were part of a larger set 350 (FC Values and Environment Related Values in Table SM1) but that were not included in our main models in Table 2, we fitted models including the whole set of variables. We also tested models involving other economic variables, including income inequality (the last four variables in Table SM1). We fitted these extra models to be sure that noy important relationships had been missed. For these extra models, we only reported the socio-economic effects that were highly significant (p-values below 0.001 or with an absolute value of mean/standard error ratio above 3.3).

Also, to check whether proportion of endemic species should be considered as a covariate in models with proportion of extinct and threatened species, as suggested by the results of Holland et al. (2009), we fitted the Null model with the proportion of endemic species as a covariate. The resulting 
models either had a poorer LOOIC than the Null model (for threatened species) or a lower LOOIC but

360 with significant effects in the unexpected, negative direction (for extinct species) so we did not

361 include them in the analyses.

362

363

Finally, to gauge the adequacy of statistical models in relation to the data, we used sampled

364

posterior goodness-of-fit p-values (Gosselin, 2011). These p-values allowed us in particular to

365

diagnose (i) the adequacy of the probability distributions used, (ii) the correlation between normalized

366 randomized quantile residuals (Dunn and Smyth, 1996) or their squared value and explanatory

367 variables or the mean of observed variables (to diagnose the link function and the specification of variance) - as in Herpigny and Gosselin (2015) -, and (iii) the spatial autocorrelation of the

369 normalized randomized quantile residuals. Given that we used around ten discrepancy functions per

370 model, only p-values below 0.005 were investigated with graphics, much as in Harrell (2001). These p-values are based on normalized transforms of data as in Gosselin (2011) and were applied to the

372 best model associated with each biodiversity variable.

373

\section{$374 \quad$ Results}

On the whole, with proportion of protected area as a dependent variable, none of the main socio-economic models was better than the Null model (Tables 3). The estimated relationships were all non-significant (Table SM3).

\begin{tabular}{|l|l|l|l|l|l|}
\hline Model name & Extinct & Threatened & Protected & SEAL & iSEAL \\
& species & species & Areas & & \\
\hline Null & 31,11 & 31,26 & $\underline{\mathbf{0 , 0 0}}$ & 46,86 & 19,93 \\
\hline
\end{tabular}




\begin{tabular}{|c|c|c|c|c|c|}
\hline eco & 5,93 & 24,43 & 10,89 & 18,26 & $\underline{\mathbf{0 , 0 0}}$ \\
\hline leco & 2,01 & 2,46 & 8,82 & $\underline{\mathbf{0 , 0 0}}$ & 0,61 \\
\hline Kuznets & 27,39 & 25,47 & 7,61 & 42,09 & 17,91 \\
\hline 1Kuznets & 32,59 & 29,41 & 4,89 & 48,01 & 19,70 \\
\hline Kuznetsa & $\underline{\mathbf{0 , 0 0}}$ & $\underline{0,00}$ & 14,82 & 12,95 & 4,80 \\
\hline 1Kuznetsa & 0,10 & 1,78 & 6,97 & 6,58 & 5,03 \\
\hline demo & 6,89 & 18,53 & 18,85 & 17,16 & $\mathbf{0 , 8 2}$ \\
\hline ldemo & 1,35 & 9,85 & 5,38 & 1,41 & 3,57 \\
\hline $\mathrm{FC}$ & 2,78 & 9,83 & 6,58 & 40,82 & 22,14 \\
\hline $\mathrm{SC}$ & 26,35 & 15,32 & 6,02 & 52,64 & 24,38 \\
\hline NGOs & 29,95 & 38,41 & 8,12 & 39,10 & 15,05 \\
\hline ERV & 20,36 & 38,27 & 3,50 & 44,85 & 22,32 \\
\hline
\end{tabular}

379 Table 3. Statistical comparison of models. Difference in Leave-one out Information Criterion

380 (LOOIC) values with the LOOIC of the best model for the different explanatory models fitted (by

381 column). The lower the LOOIC, the better the model. The best model is underlined and models with a

382 LOOIC within 6 units of the best model - i.e. relatively close to the best model - are in bold (as 
384 column) can be compared. See Tables 1 and 2 for the content of the models.

\begin{tabular}{|c|c|c|c|}
\hline Variable name & $\begin{array}{l}\text { Summary } \\
\text { statistics of } \\
\text { the estimator }\end{array}$ & p-value & $\begin{array}{l}\text { Summary } \\
\text { impact in log } \\
\text { odds ratio of an } \\
\text { increase of } 1 \\
\text { standard } \\
\text { deviation of the } \\
\text { variable }\end{array}$ \\
\hline GDPc/10000 in eco & $0.039(0.101)$ & 0.34679 & 00 \\
\hline $\mathrm{HPD} / 100$ in eco & $0.325(0.085)$ & 0.00019 & $00+$ \\
\hline $\log (\mathrm{GDPc} / 10000)$ in leco & $0.272(0.199)$ & 0.08037 & 00 \\
\hline $\log (\mathrm{HPD} / 100)$ in leco & $0.434(0.116)$ & 0.00024 & $0+$ \\
\hline GDPc/10000 in Kuznets & $0.313(0.142)$ & 0.01274 & 0 \\
\hline$(\mathrm{GDPc} / 10000)^{2}$ in Kuznets & $-0.158(0.091)$ & 0.03674 & \\
\hline
\end{tabular}




\begin{tabular}{|c|c|c|c|}
\hline $\log (\mathrm{GDPc} / 10000)$ in lKuznets & $0.413(0.263)$ & 0.0578 & 00 \\
\hline $\log (\mathrm{GDPc} / 10000)^{2}$ in lKuznets & $-0.102(0.285)$ & 0.36477 & \\
\hline GDPa/50000 in Kuznetsa & $0.71(0.191)$ & 0.00032 & $0+$ \\
\hline$(\mathrm{GDPa} / 50000)^{2}$ in Kuznetsa & $-0.153(0.098)$ & 0.05587 & 0 \\
\hline $\log (\mathrm{GDPa} / 50000)$ in 1Kuznetsa & $0.296(0.115)$ & 0.0044 & $0+$ \\
\hline $\log (\mathrm{GDPa} / 50000)^{2}$ in 1 Kuznetsa & $0.09(0.078)$ & 0.11922 & \\
\hline $\mathrm{HPDu} / 100$ in demo & $0.34(0.086)$ & 0.00019 & $00+$ \\
\hline HPDr/100 in demo & $0.278(0.487)$ & 0.27778 & 00 \\
\hline $\log (\mathrm{HPDu} / 100)$ in ldemo & $0.443(0.104)$ & 0.00013 & $0+$ \\
\hline $\log (\mathrm{HPDr} / 100)$ in ldemo & $-2.138(4.242)$ & 0.30231 & \\
\hline H.LT/10 in FC & $0.23(0.057)$ & 0.00024 & $0+$ \\
\hline H.HED/10 in FC & $0.174(0.05)$ & 0.00068 & $00+$ \\
\hline TRUSTP in SC & $-0.16(0.096)$ & 0.04626 & 0 \\
\hline TRUSTG in SC & $0.246(0.093)$ & 0.00461 & $0+$ \\
\hline MEMB.2008 in NGOs & $0.174(0.079)$ & 0.0139 & 00 \\
\hline
\end{tabular}




\begin{tabular}{|l|c|c|c|} 
CONFAE.2008 in NGOs & $-0.011(0.091)$ & 0.44712 & 00 \\
\hline REIGN.2008 in ERV & $-0.165(0.095)$ & 0.03734 & 00 \\
\hline INTERF.2008 in ERV & & & $00-$ \\
& $-0.467(0.169)$ & 0.0039 & \\
\hline
\end{tabular}

387

388 Table 4. Proportion of extinct species. Summary of the estimators of the socio-economic variables in

389 the twelve main models (all models in Table 2 except the null model) for the proportion of extinct

390 species. For magnitude analyses (last column), the results of the analyses were conclusive if $95 \%$ of

391 the odds ratio effects were in the interval $[-0.1 ; 0.1]$ (denoted as 000 and qualified as a strongly

392 negligible relationship), $[-0.5 ; 0.5]$ (denoted as 00 and qualified as a moderately negligible

393 relationship), $[-1 ; 1]$ (denoted as 0 and qualified as a weakly negligible relationship), $[0.1 ;+\infty[$

394 (denoted as + and qualified as a weakly positive relationship), $[0.5 ;+\infty[$ (denoted as ++ and qualified

395 as a moderately positive relationship), $[1 ;+\infty[$ (denoted as +++ and qualified as a strongly positive

396 relationship), $-\infty ;-0.1]$ (denoted as - and qualified as a weakly negative relationship), $]-\infty ;-0.5$ ]

397 (denoted as -- and qualified as a moderately negative relationship) and $]-\infty ;-1]$ (denoted as --- and

398 qualified as a strongly negative relationship) (as in e.g. Daniels 1983). Results were inconclusive with

399 respect to magnitude analyses if the last column was void. See Tables 1 and 2 for the content of the

400 models and the definition of the explanatory variables.

401

402

403 


\begin{tabular}{|c|c|c|c|}
\hline Variable name & $\begin{array}{c}\text { Summary } \\
\text { statistics of the } \\
\text { estimator }\end{array}$ & $\mathrm{p}$-value & $\begin{array}{l}\text { Summary impact in } \\
\text { log odds ratio of an } \\
\text { increase of } 1 \\
\text { standard deviation } \\
\text { of the variable }\end{array}$ \\
\hline GDPc/10000 in eco & $0.097(0.084)$ & 0.12161 & 00 \\
\hline $\mathrm{HPD} / 100$ in eco & $0.143(0.078)$ & 0.03224 & 00 \\
\hline $\log (\mathrm{GDPc} / 10000)$ in leco & $0.283(0.148)$ & 0.02691 & 00 \\
\hline $\log (\mathrm{HPD} / 100)$ in leco & $0.259(0.087)$ & 0.00266 & $00+$ \\
\hline GDPc/10000 in Kuznets & $0.223(0.096)$ & 0.01127 & 00 \\
\hline$(\mathrm{GDPc} / 10000)^{2}$ in Kuznets & $-0.093(0.06)$ & 0.06117 & \\
\hline $\log (\mathrm{GDPc} / 10000)$ in lKuznets & $0.34(0.182)$ & 0.03235 & 00 \\
\hline $\log (\mathrm{GDPc} / 10000)^{2}$ in 1Kuznets & $-0.019(0.19)$ & 0.46242 & \\
\hline GDPa/50000 in Kuznetsa & $0.623(0.153)$ & 0.00022 & $0+$ \\
\hline
\end{tabular}




\begin{tabular}{|c|c|c|c|}
\hline$(\mathrm{GDPa} / 50000)^{2}$ in Kuznetsa & $-0.237(0.081)$ & 0.00258 & $0-$ \\
\hline $\log (\mathrm{GDPa} / 50000)$ in 1 Kuznetsa & $0.29(0.091)$ & 0.00208 & $0+$ \\
\hline $\log (\mathrm{GDPa} / 50000)^{2}$ in 1 Kuznetsa & $-0.027(0.066)$ & 0.32468 & \\
\hline $\mathrm{HPDu} / 100 \mathrm{in}$ demo & $0.132(0.078)$ & 0.04234 & 00 \\
\hline HPDr/100 in demo & $0.703(0.419)$ & 0.04708 & 00 \\
\hline $\log (\mathrm{HPDu} / 100)$ in ldemo & $0.255(0.087)$ & 0.00355 & $00+$ \\
\hline $\log (\mathrm{HPDr} / 100)$ in ldemo & $1.363(4.081)$ & 0.36571 & \\
\hline H.LT/10 in FC & $0.13(0.047)$ & 0.00412 & 00 \\
\hline H.HED/10 in FC & $0.12(0.043)$ & 0.00342 & 00 \\
\hline TRUSTP in SC & $-0.156(0.068)$ & 0.01296 & 00 \\
\hline TRUSTG in SC & $0.156(0.066)$ & 0.01137 & 00 \\
\hline MEMB.2008 in NGOs & $0.063(0.064)$ & 0.15124 & 00 \\
\hline CONFAE.2008 in NGOs & $0.06(0.071)$ & 0.19241 & 00 \\
\hline REIGN.2008 in ERVERV & $-0.108(0.077)$ & 0.07665 & 00 \\
\hline INTERF.2008 in ERVERV & $-0.037(0.145)$ & 0.39607 & 00 \\
\hline
\end{tabular}


Table 5. Proportion of threatened species. Summary of the estimators of the socio-economic variables

406 in the twelve main models (all models in Table 2 except the null model) for the proportion of

407 threatened species. See Table 4 legend for the meaning of the signs used for magnitude analysis (last

408 column). See Tables 1 and 2 for the content of the models and the definition of the explanatory

409 variables.

410

We observed more significant relationships for the proportion of threatened species, for which

412 the models with economic variables (leco, Kuznetsa \& lKuznetsa models) were the best models 413 indeed, far better than the null model (Tables $3 \&$ 5). Significant relationships (second column of 414 Table 5) involved GDP (both per capita GDPc and per area GDPa), HPD (and urban HPDu) as well as 415 social variables related to Fundamental Cultural values (long-term orientation and hedonism variables 416 in the FC model, and Trust in other people (TRUSTP) and Trust in the national government 417 (TRUSTG) in the SC model. Among these, only the relationships related to GDPa in the Kuznets-type 418 models and those related to log-transformed HPD or urban HPD (HPDu) were non-negligible (last 419 column of Table 5). All these relationships were positive except for the quadratic terms in the 420 Kuznets-type models and Trust in other people (TRUSTP), which were negative. Clear relationships were found for the proportion of extinct species as well (Tables $3 \& 4$ ): the best models (the models with economic variables and the Fundamental Cultural FC model) were clearly better than the null model: relationships were more significant, and there were more positive or negative non-negligible relationships (last column of Table 4) than for the proportion of threatened species. The two FC variables (long-term orientation H.LT and hedonism H.HED) had a positive nonnegligible relationship with the proportion of extinct species - as did GDPa, HPD, HPDu and Trust in Government (TRUSTG) - while the opinion that "interference with nature is often disastrous" (INTERF.2008) had a negative non-negligible relationship (Table 4). In addition, some other variables displayed a weak but still significant relationship: various GDPc metrics (positive relationships, except for one negative relationship for the square of GDPC in Kuznets); Trust in 431 People (TRUSTP; negative relationship); membership in environmental associations (MEMB.2008; 432 positive relationship); and belief that "man should reign over nature" (REIGN.2008; negative effect). 
434 suggested that the log-transformed versions of the economic and demographic models (leco and 435 ldemo) had the best explanatory capacity (Table 3). Non-negligible positive relationships were found 436 with the logarithm of the HPD variables as well as with GDPa, Fundamental Cultural H.LT and 437 H.HED variables and membership in environmental associations (MEMB.2008). Non-negligible 438 negative relationships were found with the square terms of GDPc and GDPa in the Kuznets-type 439 models (Table 6). The dynamics of sealed areas (iSEAL; Tables 3 and 7) gave rather similar results to 440 those from the models with the proportion of extinct species (except that the FC models lost 441 explanatory power and that economic and demographic models had good explanatory power whether 442 they were log-transformed or not). HPD and HPDu were highly significant and had a non-negligible 443 positive impact, which was also observed for GDPa.

\begin{tabular}{|c|c|c|c|}
\hline Variable name & $\begin{array}{l}\text { Summary } \\
\text { statistics of } \\
\text { the estimator }\end{array}$ & p-value & $\begin{array}{l}\text { Summary impact in } \\
\text { log odds ratio of an } \\
\text { increase of } 1 \text { standard } \\
\text { deviation of the } \\
\text { variable }\end{array}$ \\
\hline GDPc/10000 in eco & $0.007(0.072)$ & 0.45115 & 00 \\
\hline HPD/100 in eco & $0.446(0.052)$ & 0.00005 & $0+$ \\
\hline $\log (\mathrm{GDPc} / 10000)$ in leco & $0.277(0.131)$ & 0.01693 & 00 \\
\hline
\end{tabular}




\begin{tabular}{|c|c|c|c|}
\hline $\log (\mathrm{HPD} / 100)$ in leco & $0.767(0.088)$ & 0.00005 & $0++$ \\
\hline GDPc/10000 in Kuznets & $0.331(0.13)$ & 0.00448 & $0+$ \\
\hline$(\mathrm{GDPc} / 10000)^{2}$ in Kuznets & $-0.247(0.084)$ & 0.00066 & -- \\
\hline $\log (\mathrm{GDPc} / 10000)$ in 1Kuznets & $0.452(0.259)$ & 0.03379 & 00 \\
\hline $\log (\mathrm{GDPc} / 10000)^{2}$ in lKuznets & $-0.716(0.41)$ & 0.03131 & -- \\
\hline GDPa/50000 in Kuznetsa & $0.899(0.135)$ & 0.00005 & $0++$ \\
\hline$(\mathrm{GDPa} / 50000)^{2}$ in Kuznetsa & $-0.163(0.065)$ & 0.00729 & $0-$ \\
\hline $\log (\mathrm{GDPa} / 50000)$ in 1 Kuznetsa & $0.545(0.098)$ & 0.00005 & $0+$ \\
\hline $\log (\mathrm{GDPa} / 50000)^{2}$ in 1Kuznetsa & $0.042(0.06)$ & 0.23333 & \\
\hline $\mathrm{HPDu} / 100$ in demo & $0.438(0.053)$ & 0.00005 & $0+$ \\
\hline HPDr/100 in demo & $0.597(0.405)$ & 0.06555 & 00 \\
\hline $\log (\mathrm{HPDu} / 100)$ in ldemo & $0.73(0.068)$ & 0.00005 & $0++$ \\
\hline $\log (\mathrm{HPDr} / 100)$ in ldemo & $-0.012(0.05)$ & 0.38822 & 00 \\
\hline
\end{tabular}




\begin{tabular}{|l|c|c|c|} 
H.LT/10 in FC & $0.208(0.072)$ & 0.00312 & $0+$ \\
\hline H.HED/10 in FC & $0.182(0.062)$ & 0.00285 & $0+$ \\
\hline TRUSTP in SC & & & 00 \\
\hline TRUSTG in SC & $-0.035(0.08)$ & 0.32184 & 00 \\
\hline MEMB.2008 in NGOs & $0.034(0.092)$ & 0.34344 & $0+$ \\
\hline CONFAE.2008 in NGOs & & & 00 \\
\hline REIGN.2008 in ERV & $0.43(0.113)$ & 0.0021 & $00-$ \\
\hline INTERF.2008 in ERV & & & $0.09(0.075)$ \\
& & 0.11056 & \\
\hline
\end{tabular}

446 Table 6. Proportion of Sealed Area. Summary of the estimators of the socio-economic variables in the

447 twelve main models (all models in Table 2 except the null model) for the proportion of Sealed Area.

448 See Table 4 legend for the meaning of the signs used for magnitude analysis (last column). See Tables

4491 and 2 for the content of the models and the definition of the explanatory variables.

\begin{tabular}{|l|l|l|l|}
\hline Variable name & Summary & p-value & Summary impact in \\
statistics of & & log odds ratio of an \\
the estimator & & increase of 1 standard \\
deviation of the \\
variable
\end{tabular}




\begin{tabular}{|c|c|c|c|}
\hline GDPc/10000 in eco & $-0.02(0.071)$ & 0.39303 & 00 \\
\hline $\mathrm{HPD} / 100$ in eco & $0.326(0.056)$ & 0.00005 & $00+$ \\
\hline $\log (\mathrm{GDPc} / 10000)$ in leco & $0.133(0.145)$ & 0.17557 & 00 \\
\hline $\log (\mathrm{HPD} / 100)$ in leco & $0.483(0.101)$ & 0.00005 & $0+$ \\
\hline GDPc/10000 in Kuznets & $0.188(0.102)$ & 0.0306 & 00 \\
\hline$(G D P c / 10000)^{2}$ in Kuznets & $-0.161(0.074)$ & 0.00847 & - \\
\hline $\log (\mathrm{GDPc} / 10000)$ in lKuznets & $0.285(0.202)$ & 0.07194 & 00 \\
\hline $\log (\mathrm{GDPc} / 10000)^{2}$ in 1Kuznets & $-0.513(0.339)$ & 0.05544 & \\
\hline GDPa/50000 in Kuznetsa & $0.437(0.144)$ & 0.00282 & $0+$ \\
\hline$(\mathrm{GDPa} / 50000)^{2}$ in Kuznetsa & $-0.019(0.071)$ & 0.39134 & 00 \\
\hline $\log (\mathrm{GDPa} / 50000)$ in 1 Kuznetsa & $0.339(0.095)$ & 0.00028 & $0+$ \\
\hline $\log (\mathrm{GDPa} / 50000)^{2}$ in 1 Kuznetsa & $0.015(0.069)$ & 0.39856 & \\
\hline
\end{tabular}




\begin{tabular}{|c|c|c|c|}
\hline $\mathrm{HPDu} / 100$ in demo & $0.301(0.056)$ & 0.00007 & $00+$ \\
\hline HPDr/100 in demo & $0.575(0.395)$ & 0.06912 & 00 \\
\hline $\log (\mathrm{HPDu} / 100)$ in ldemo & $0.441(0.081)$ & 0.00002 & $0+$ \\
\hline $\log (\mathrm{HPDr} / 100)$ in ldemo & $-0.002(0.066)$ & 0.46199 & 00 \\
\hline H.LT/10 in FC & $0.089(0.066)$ & 0.0872 & 00 \\
\hline H.HED/10 in FC & $0.065(0.056)$ & 0.12368 & 00 \\
\hline TRUSTP in SC & $-0.016(0.068)$ & 0.40567 & 00 \\
\hline TRUSTG in VSC & $0.004(0.074)$ & 0.47225 & 00 \\
\hline MEMB.2008 in NGOs & $0.317(0.104)$ & 0.00746 & $0+$ \\
\hline CONFAE.2008 in NGOs & $0.068(0.062)$ & 0.13418 & 00 \\
\hline REIGN.2008 in ERV & $-0.144(0.077)$ & 0.02876 & 00 \\
\hline INTERF.2008 in ERV & $-0.184(0.143)$ & 0.10071 & 00 \\
\hline
\end{tabular}

454 Table 7. Increment of the proportion of dynamic of Sealed Area. Summary of the estimators of the 455 socio-economic variables in the twelve main models (all models in Table 2 except the null model) for 456 the increment between 2006 and 2009 of the proportion of Sealed Area. See Table 4 legend for the 457 meaning of the signs used for magnitude analysis (last column). See Tables 1 and 2 for the content of 458 the models and the definition of the explanatory variables. 
461 to our standards for additional variables was the opinion that "freedom is more important than 462 equality" (FREED.2008), which was positively associated with the proportion of Sealed area 463 (SEAL,cf. Table SM4).

464

465

Generally, we did not detect any very significant discrepancy between the data and the best model by using posterior goodness-of-fit p-values for the proportion of protected area, sealed area, increase in sealed area or extinct species. Skewness of normalized data $(\mathrm{p}<0.001)$ revealed a significant discrepancy, however, for the best model for Threatened.

469

\section{Discussion}

471 Patterns of biodiversity loss are, of course, more complicated than shown in the simplemodels we fitted. Our results highlight a new potential indicator for the ecological footprint, gross domestic product per area (GDPa), which appears to robustly explain the two indicators of State of biodiversity

474 we analyzed (the proportions of extinct and threatened species). Our results also indicate the 475 prominent role of human population density (HPD), especially when log-transformed, except for the 476 proportion of protected area.

\section{Empirical Findings}

478 Surprisingly, we did not find any strong relationship between the proportion of protected area and our 479 socio-economic variables. Indeed, none of these relationships was significant, even at the 5\% level 480 (Table SM3). This is in contrast with the results summarized by Luck (2007) who reported a negative relationship between human population density (HPD) and protected areas - however, the metrics Luck considered for protected areas, from area proportion to absolute area, were not all consistent with area proportion as used in our study. 
484 In an extensive study, Blaikie and Brookfield (2013) advocated the need to implement land

485 management practices that would avoid land degradation induced by human activities. Following this

486 seminal work, a vast amount of literature was published on the issue of land degradation or land

487 sealing, which mostly studied the factors determining the degree of land degradation (Salvati and

488 Zitti, 2009; Kizos et al, 2016). There are fewer studies about the impact of soil sealing on biodiversity

489 at a macro (cross-country) level. Our results reveal the same trends as those reported by Luck (2007)

490 for HPD and protected areas (see above): our best models involved HPD, HPDu or GDPa (Table 3)

491 and the effects of HDP and HPDu were significant and mildly strongly positive (Tables 6 \& 7).

492 If previous references are scarce on the link between socio-economic variables and the Pressure and

493 Response indicators we used, the literature is more abundant on our two State indicators - the

494 proportion of threatened species and, to an even greater extent, the proportion of extinct species.

495 Indeed, regarding the statistical models for the proportion of threatened species, our results are very

496 much in agreement with those of Gosselin (2015) in terms of the statistical significance of the

497 relationships for economic variables. Our model eco is a simplified version of the models in Gosselin

498 (2015). As did Gosselin (2015), we found that, for threatened species, these models are not

499 particularly better than the null model as judged from their LOOIC value (cf. Table 3). Noticeably, a

500 similar model with log-transformed variables yielded much better results (model leco in Table 3). The

501 two socio-economic variables that stand out are HPD and GDPa - a relatively new metric of

502 development intensity calculated by unit of area and not per capita as usual. HPD and GDPa are

503 highly correlated (cf. Figure SM1), in agreement with Liu et al. (2005) - and their associated models

504 (IKuznetsa, Kuznetsa \& leco) stand out as the best explanatory variables/models for variations in the

505 proportion of both extinct and threatened species in European countries (Tables 3, 4 and 5). Our

506 results are quite consistent with previous findings where HPD was significantly and positively

507 associated to the proportion of threatened or extinct species (Hoffmann, 2004; McPherson and

508 Nieswiadomy, 2005; Luck, 2007; Pandit and Laband, 2007). In contrast, we did not find any

509 significantrelationship with income inequality, as had been reported by Holland et al. (2009) and

510 Mikkelson et al. (2007). 
511 In terms of magnitude, starting with proportions of extinct species and threatened species of 3.0 and

$51230.0 \%$ respectively, doubling HPD would correspond to increasing these proportions to $4.0(+/-0.3) \%$

513 and $33.9(+/-1.4) \%$ respectively, while doubling GDPa would yield $3.7(+/-0.3) \%$ and $34.4(+/-1.4)$

$514 \%$ respectively. We therefore judge that these effects are of intermediate strength.

515 Our results seem to validate some sort of "Kuznets curve", involving either the logarithm of GDPa or

516 of the very correlated HPD. This implies that human pressure on biodiversity should tend to slow

517 down as human activity - measured through either HPD or GDPa - grows. However, this does not

518 mean that the relationship between human pressure and biodiversity will turn negative for high levels

519 of human pressure since in the logarithm version of the Kuznets model with GDPa the quadratic term

520 is non-significant for the proportion of both extinct and threatened species. We therefore have no sign

521 that continuing growth will have a positive impact on biodiversity for high levels of development.

522 Of course, testing our results on a larger sample of countries would also be pertinent. However, the

523 data we used for extinct and threatened species were at the national scale (cf. Essl et al., 2013), not at

524 the global scale defined by the IUCN and used in many other publications (e.g. McKinney, 2002a,

525 2002b; Hoffmann, 2004; Clausen and York, 2008; Holland et al., 2009). Despite ongoing initiatives,

526 such national-scale red lists are, to the best of our knowledge, not yet available for an extended list of

527 countries outside Europe. It would also be interesting to include other indicators of human activity

528 than the ones studied here. Candidates include total human population (and not its density; cf.

529 McKinney, 2002a; Brown and Laband, 2006; Clausen and York, 2008), spatial concentration of

530 population (Pandit and Laband, 2007 in line with considerations in e.g. Ehrlich \& Holdren, 1971), or

531 the variables devised by Hoffmann (2004) related to increases over time in HPD or GDP, or levels of

532 energy consumption.

\section{Potential Mechanisms}

534 Our results clarify the potential mechanisms behind biodiversity erosion at the country level. Indeed,

535 the high number of theoretical models attempting to explain the Environmental Kuznets Curve (EKC)

536 make it difficult to discriminate among mechanisms (Dinda, 2004; Kijima et al., 2010). The lack of 
537 robustness for empirical results on EKC, as well as the curve's loose theoretical foundations, have led

538 several authors to suggest giving up the search for relations between aggregate data and focusing 539 instead on the processes at play in each national situation (Stern 2004). In this vein, integrative 540 models have been developed to take into account a variety of contextual parameters (e.g Verboom et 541 al., 2007). The search for macro-relations goes on, however, in the context of growth theory. For example, Brock and Taylor (2010) show that the EKC and many empirical results can be derived as an extension of a basic growth model by adding a pollution compartment. Our results using GDP per

544 area provide a strong argument that economic activity is a major driving force for biodiversity 545 erosion.

546 Even if our models with sociological variables have a lower predictive power than our best economic 547 models, two fundamental cultural (FC) variables seemed to have a robust effect: "Long-term orientation" (H.LT) and "Hedonism" (H.HED). Both had a positive sign for the two State indicators and for the sealed area Pressure indicator - with non-negligible relationships for the proportion of extinct species and sealed area -, thus indicating that these variables negatively impact biodiversity indicators related to past trends (extinct species and sealed area) more than they do indicators related to current trends (threatened species and increment in sealed area). While this result is not surprising for hedonism, which could translate into a preference for material goods over preserving nature, it is more surprising for "long-term orientation". In fact, both seeking profit (hedonism) and investing (long-term) are core values of capitalism. Consequently, the causal chain seems to run from fundamental cultural values (FC) to economic growth, then to biodiversity. Interpersonal trust (TRUSTP) reaches significant negative estimates for both biodiversity State indicators; an increase in Interpersonal trust leads to a decrease in biodiversity erosion. This result is interesting because trust is also generally considered to be a key component of social capital, which promotes economic growth. The fact that interpersonal trust is also positively associated with biodiversity suggests that a high-quality social life acts positively on concern for the environment.

563 Surprisingly, trust in government (TRUSTG) is positively associated with biodiversity erosion 564 (whereas, classically, it is also positively correlated with economic activity). One explanation could 
565 be that collective action (or a demand for action on the part of the government) may act either in favor

566 of the environment or against it, in order to promote economic interests, for instance.

567

568 Membership in environmental associations (MEMB.2008) was often positively associated with biodiversity erosion or land sealing. This could reflect a reaction to a deteriorated state of the environment, rather than signal the existence of fundamental environmental values (this variable might therefore be classified as a Response indicator in the DPSIR scheme). The belief that

572 interference with nature is often disastrous (INTERF.2008) was negatively associated with

573 biodiversity erosion only for extinct species, suggesting a weak relationship between environmental 574 concern and biodiversity. Lastly, and surprisingly, the belief that "man should reign over nature" 575 (REIGN.2008) was positively associated with some indicators of biodiversity, i.e. associated with less soil sealing or a lower proportion of extinct species, suggesting that "reign over nature" may convey a protective, stewardship view, and not only an extractive one.

\section{Policy implications}

580 The main driver of biodiversity erosion seems to be economic activity. Our results suggest that the

581 spatial density of economic activity (economic growth; variable GDPa) or human population (variable

582 HPD) in particular are key variables that are positively related to land sealing levels - interpreted here

583 as a pressure on biodiversity - and to both past and current biodiversity erosion. Echoing e.g. Ehrlich and Holdren (1971), our results clearly indicate that the spatial density of human activity should be part of political analyses related to biodiversity. Variables related to spatial density of human activity should integrate systems of biodiversity indicators.

588 Our results may seem discouraging: it is difficult to promote policies which discourage economic 589 growth in a period of economic crisis. However, information and education can alter social and cultural attitudes, for example by lowering "hedonism", which our results show to be detrimental to 
591 biodiversity. Brahic and Rambonilaza (2015) have shown, for example, that providing visitors with

592 information on the quality of forest ecosystems significantly alters the value they attribute to these

593 ecosystems. Education and information often involve associations, whose activity in turn reinforces

594 social capital and trust in other people, which, as we have seen, are conducive to both economic 595 prosperity and a better state of biodiversity. Increasing social trust should therefore be an overarching government objective.

597

598 Land use appears to be a crucial aspect in both biodiversity protection and the interrelation betewen 599 biodiversity and economic activity. That is why ecological compensation (or biodiversity offset) 600 policies are crucial in favoring cohabitation between economic activity and ecosystem quality (Bull et 601 al., 2013). Such policies have been adopted in many countries; they impose compensation for 602 biodiversity loss on any project which negatively impacts natural habitats. If correctly designed, offsetting policies can even create new jobs (restoration activities or ecological engineering,

604 alternative forms of agriculture and tourism). In practice however, they are often poorly implemented, 605 due to the difficulty of clearly evaluating ecological impacts and to the lack of effective monitoring 606 and enforcement systems.

607

\section{Conclusion}

609 Despite our small sample size, our results allow a general picture to emerge. Economic activity 610 appears to be a strong component of human pressure on biodiversity, and the spatial density of this

611 pressure - either in terms of economic growth or human population - should be taken into account.

612 Our results seem to validate the "Kuznets curve" when the spatial density of growth is considered 613 instead of per capita growth, which indicates that human pressure should tend to slow down as the spatial density of human activity increases. However, we should not conclude that continuing growth will have a positive impact on biodiversity, first because the decrease shown by the Kutznets curve 
616 might be due to the exportation of environmental pressures to poorer countries, and second, because

617 there is no sign of negative relationships for high levels of growth in models where growth has been

618 log-transformed.

619 The role of social values is not easy to decipher, but social trust, and to some extent concern for the

620

621

622

623

624

625

626

627

628

629

630

631

632

633

634

635

636

637

638

639

640

641 environment, seem to favor the preservation of biodiversity. This is good news since social trust is also known to positively influence economic performance, and should be a natural target for policymakers. Societies that function well as a whole are more likely to sustain both prosperity and the quality of the environment.

Overall, our results cast a new light on old issues. They call for further studies around the new metric, GDP per unit area, which seems more relevant than the classical GDP per capita, studies with more data or with data reflecting smaller geographical scales. Finally, relationships and potential causalities should be tested within the DPSIR framework, which would require new indicators for the other components in that framework.

Acknowledgements. This research was supported by the French ministry in charge of Ecology through the DEB-Irstea convention (Action S). We warmly thank Victoria Moore and Marion Gosselin for their help in improving the clarity and style of the English manuscript.

\section{References:}

Arrhenius, O., 1921. Species and area. J. Ecol. 9, 95-99.

Asafu-Adjaye, J., 2003. Biodiversity loss and economic growth: A cross-country analysis. Contemp. Econ. Pol. 21, 173-185.

Barbier, S., Chevalier, R., Loussot, P., Bergès, L., Gosselin, F., 2009. Improving biodiversity indicators of sustainable forest management: tree genus abundance rather than tree genus richness and 
642 dominance for understory vegetation in French lowland oak hornbeam forests. For. Ecol. Manag. 258, 643 S176-S186.

644 Bjørnskow, C., 2006. The multiple facets of social capital. Eur. J.Political Econ., 22, 22-40.

645 Blaikie, P.M., Brookfield H., 2013. Land degradation and society. Routledge Revival, London.

646 Brahic E., Rambonilaza T., 2015. The impact of information on public preferences for forest

647 biodiversity preservation: a split-sample test with choice experiment method. Revue d'économie

648 politique $125,152-171$.

649 Brock W.A., Taylor M.S., 2010. The Green Solow model. J. Econ. Growth 15, 127-153.

650 Brown, J.H., 1999. Macroecology: Progress and prospect. Oikos 87,3-14.

651 Brown, R.M., Laband, D.N., 2006. Species imperilment and spatial patterns of development in the 652 United States. Cons. Biol. 20, 239-244.

653 Bull, J.W., Suttle, K.B., Gordon, A., Singh, N.J., Milner-Gulland, E.J., 2013. Biodiversity offsets in 654 theory and practice. Oryx 47, 369-380.

655 Butchart, S.H., Walpole, M., Collen, B., Van Strien, A., Scharlemann, J.P. et al., 2010. Global

656 biodiversity: Indicators of recent declines. Science 328, 1164-1168.

657 Callois, J.M., Schmitt. B., 2009. The role of social capital components on local economic growth: the 658 case of French rural areas. Rev. Agric. Envir. Studies 90, 257-286.

659 Camp, R.J., Seavy, N.E., Gorresen, P.M., Reynolds, M.H., 2008. A statistical test to show negligible 660 trend: Comment. Ecology 89, 1469-1472.

661 Chambers, D., Hamer, S., 2012. Culture and growth: Some empirical evidence. Bull. Econ. Res. 64, $662 \quad 549-564$.

663 Clausen, R., York, R., 2008. Global biodiversity decline of marine and freshwater fish: A cross664 national analysis of economic, demographic, and ecological influences. Social Sci. Res. 37, 13106651320.

666 Coleman, J. S., 1988. Social capital in the creation of human capital. Amer. J. Sociol. 94, S95-S120.

667 Daniels, S.R., Greenberg, R.S., Ibrahim, M.A., 1983. Etiologic research in pediatric epidemiology. J. 668 Pediatrics 102, 494-504. 
669 Dasgupta, P., 2000. Economic Progress and the Idea of Social Capital, in: Dasgupta, P., Serageldin, I.

670 (Eds), Social capital: A multifaceted perspective.. The World Bank, Washington DC, pp. 325-424.

671 Dietz, T., 2017. Drivers of human stress on the environment in the twenty-first century. Annu. Rev.

672 Envir. Resources 42, 189-213.

673 Dinda, S., 2004. Environmental Kuznets Curve hypothesis: A survey. Ecol. Econ. 49, 431-455.

674 Dullinger, S., Essl, F., Rabitsch, W., Erb, K.H., Gingrich, S. et al., 2013. Europe's other debt crisis 675 caused by the long legacy of future extinctions. Proc. Nat. Acad. Sci. USA 110, 7342-7347.

676 Dunn, P.K., Smyth, G.K., 1996. Randomized quantile residuals. Journal of Computational and 677 Graphical Statistics 5, 236-244.

678 Ehrlich, P.R., Holdren, J.P., 1971. Impact of population growth. Science 171, 1212-1217.

679 Essl, F., Moser, D., Dirnböck, T., Dullinger, S., Milasowszky, N. et al., 2013. Native, alien, endemic, 680 threatened, and extinct species diversity in European countries. Biol. Cons. 164, 90-97.

681 Fahrig, L., 2003. Effects of Habitat Fragmentation on Biodiversity. Annual Review of Ecology and 682 Systematics 34, 487-515.

683 Forest Europe, UNECE, FAO, 2011. State of Europe's forests 2011. Status and trends in Sustainable 684 Forest Management in Europe. FOREST EUROPE Liaison Unit Oslo.

685 Forest Europe. 2015. State of Europe's forests 2015.- FAO \& EFI.

686 Gari, S.R., Newton, A., Icely, J.D., 2015. A review of the application and evolution of the DPSIR 687 framework with an emphasis on coastal social-ecological systems. Ocean Coast. Manage. 103, 63-77.

688 Gaston, K.J., Blackburn, T.M., 1999. A critique for macroecology. Oikos 84, 353-368.

689 Gelman, A., Carlin, J.B., Stern, H.S., Rubin, D.B., 2004. Bayesian Data Analysis, second ed..

690 Chapman \& Hall, Boca Raton.

691 Gosselin, F., 2011. A New Calibrated Bayesian Internal Goodness-of-Fit Method: Sampled Posterior 692 p-values as Simple and General p-values that Allow Double Use of the Data. PLOS ONE 6, e14770. 693 Gosselin, F., 2015. Reevaluating Europe's other debt with improved statistical tools. Biodiv. Cons. $69424,205-211$.

695 Harrell, F.E., 2001. Regression Modeling Strategies, With Applications to Linear Models, Logistic 696 Regression, and Survival Analysis. Springer, New York, USA. 
697 Herpigny, B., Gosselin, F., 2015. Analyzing plant cover class data quantitatively: customized

698 cumulative zero-inflated beta distributions show promising results. Ecol. Informatics 26, 18-26.

699 Hoffmann, J.P., 2004. Social and environmental influences on endangered species: a cross-national 700 study. Sociol. Perspect. 47, 79-107.

701 Hofstede, G., 1980. Culture's Consequences: International Differences in Work-related Values.

702 Thousand Oaks, CA: Sage.

703 Holland, T.G., Peterson, G.D., Gonzalez, A., 2009. A cross-national analysis of how economic 704 inequality predicts biodiversity loss. Cons. Biol. 23, 1304-1313.

705 Kaufmann, R.K., Davidsdottir, B., Garnham, S., Pauly, P., 1998. The determinants of atmospheric

706 SO2 concentrations: reconsidering the environmental Kuznets curve. Ecol. Econ. 25, 209-220.

707 Kijima M., Nishide K., Ohyama A., 2010. Economic models for the environmental Kuznets curve: A

708

709

710

711

712

713

714

715

716

717

718

719

720

721

722

723

724 survey. J. Econ. Dynam. Control 34, 1187-1201.

Kizos, T., Tsilimigkas, G., Karampela, S., 2016. What drives built-up area expansion on islands? Using soil sealing indicators to estimate built-up area patterns on Aegean islands, Greece. Tijdschrift voor Economische en Sociale Geografie 108, 836-853.

Krautkraemer, J.A. 1995. Incentives, development and population: a growth-theoretic perspective, in: Swanson, T.M. (Ed.),. The economics and ecology of biodiversity decline: the forces driving global change. Cambridge University Press.

Liu, J., Liang, S.-C., Liu, F.-H., Wang, R.-Q., Dong, M., 2005. Invasive Alien Plant Species in China: Regional Distribution Patterns. Divers. Distrib. 11, 341-347.

Luck, G.W., 2007. A review of the relationships between human population density and biodiversity. Biol. Rev. 82, 607-645.

McKinney, M.L., 2002a. Why larger nations have disproportionate threat rates: Area increases endemism and human population size. Biodiv. Cons. 11, 1317-1325.

McKinney, M.L., 2002b. Effects of national conservation spending and amount of protected area on species threat rates. Cons. Biol. 16, 539-543.

McPherson, M.A., Nieswiadomy, M.L., 2005. Environmental Kuznets curve: Threatened species and spatial effects. Ecological Economics 55, 395-407. 
725 Mikkelson, G.M., Gonzalez, A., Peterson, G.D., 2007. Economic inequality predicts biodiversity loss. 726 PLOS ONE 2, e444.

727 Millar, R.B. 2009. Comparison of hierarchical bayesian models for overdispersed count data using 728 DIC and Bayes' factors. Biometrics 65, 962-969.

729 Millar, R.B., 2017. Conditional vs marginal estimation of the predictive loss of hierarchical models 730 using WAIC and cross-validation. Statistics and Computing 28, 375-385.

731 Panayotou, T., 1997. Demystifying the environmental Kuznets curve: turning a black box into a 732 policy tool. Envir. Develop. Econ. 2, 465-484.

733 Pandit, R., Laband, D.N., 2007. Threatened species and the spatial concentration of humans. Biodiv. 734 Cons. 16, 235-244.

735 Peters, R.H., 1991. A critique for ecology. Cambridge University Press, Cambridge.

736 R Core Team,2016. R: A language and environment for statistical computing. 3.3.2. R Foundation for 737 Statistical Computing, Vienna, Austria.

738 Salvati, L., Zitti, M., 2009. Assessing the impact of ecological and economic factors on land 739 degradation vulnerability through multiway analysis. Ecological Indicators 9, 357-363.

740 Selden T.M., Song D., 1994. Environmental quality and development: is there a Kuznets curve for air 741 pollution emissions? J. Envir. Econ. Manag. 27, 147-162.

742 Shafik, N., 1994. Economic development and environmental quality: An econometric analysis. 743 Oxford Econ. Papers 46, 757-773.

744 Stan Development Team, 2015. Stan Modelling language User's guide and reference manual, V2.6.2.

745 Stern, D.I., 2004. The Rise and Fall of the Environmental Kuznets Curve. World Dev. 32, 1419-1439.

746 Vehtari, A., Gelman, A., Gabry, J., 2016. Practical Bayesian model evaluation using leave-one-out 747 cross-validation and WAIC. Statist. Comput. 5, 1413-1432.

748 Verboom, J., Alkemade, R., Klijn, J., Metzger, M.J., Reijnen, R., 2007. Combining biodiversity 749 modeling with political and economic development scenarios for 25 EU countries. Ecol. Econ. 62, $750 \quad 267-276$.

751 Willis, J. C., 1922. Age and area: a study in geographical distribution and origin of species.

752 Cambridge University Press, Cambridge. 
753 Wright, D.H., 1990. Human impacts on energy flow through natural ecosystems, and implications for 754 species endangerment. Ambio 19, 189-194.

755 Zak, P. J., Knack, S., 2001. Trust and Growth. Econom. J. 111, 295-321.

756 